\title{
LA NACIÓN MEXICANA Y EL COLOSO DE EUROPA. UN ENSAYO DE IGNACIO OrozCO
}

VÍCTOR OROZCO

\section{RESUMEN}

1

1 presente artículo es un capítulo del libro en prensa "Ignacio Orozco Sandoval. La gesta de un republicano olvidado”. Lo ofrezco de esta manera a los lectores de Chihuahua Hoy, porque tiene autonomía respecto al resto de la biografía del coronel juarista, de quien expongo en líneas abajo una breve semblanza. Me parece que este adelanto de la obra puede ser útil para despertar el interés en su lectura posterior, dedicada al tránsito de este abogado chihuahuense por los escenarios históricos de su época y que ha sido estudiado fragmentariamente y con múltiples errores, producto de una deficiente investigación y carencia de materiales.

Palabras clave: Chihuahua, Ignacio Orozco, Benito Juárez, Nación, República, Francia, Liberales.

1 Historiador, maestro emérito de la Universidad Autónoma de Ciudad Juárez, miembro corresponsal de la Academia Mexicana de Historia. 


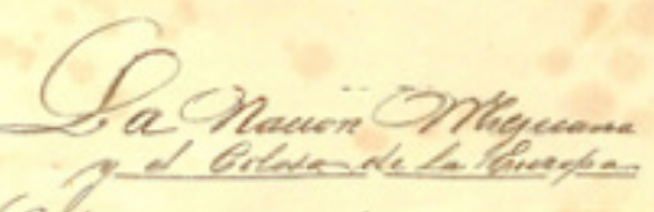

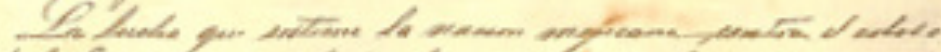

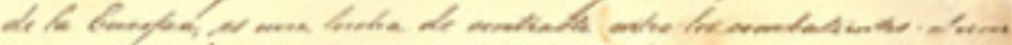

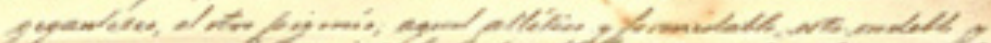

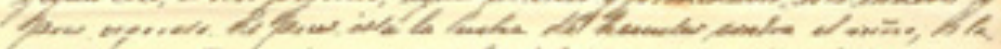

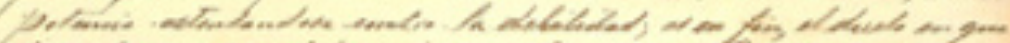

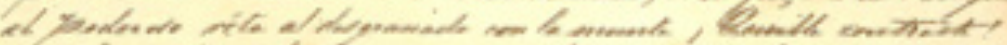

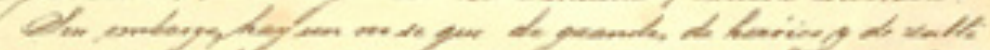

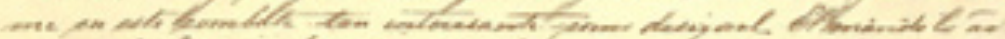

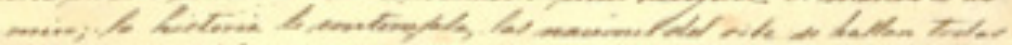

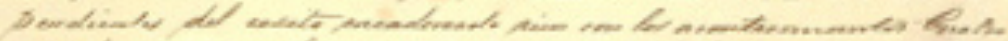

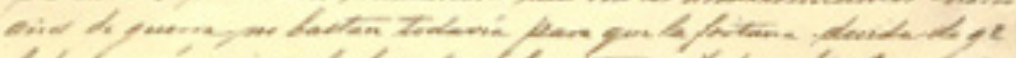

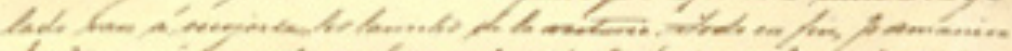

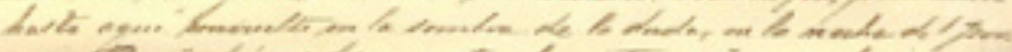

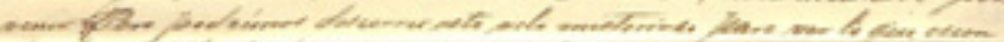
A) wi 0 -

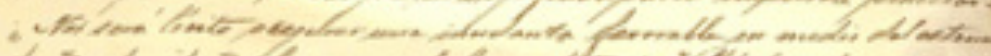

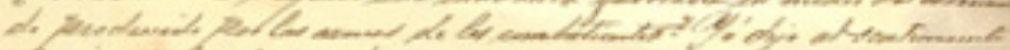

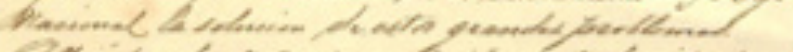

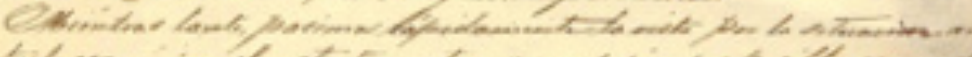

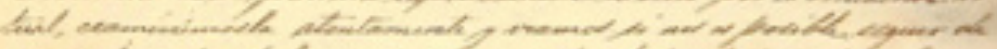

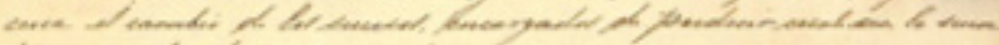

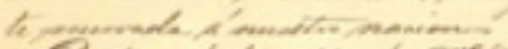

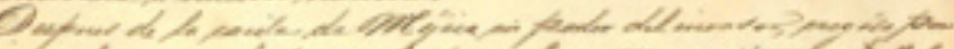

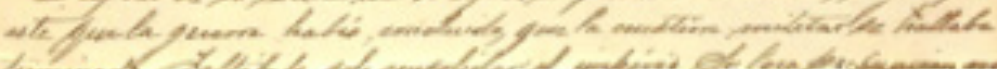

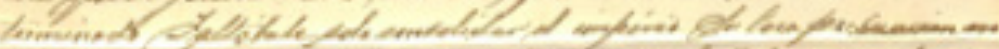

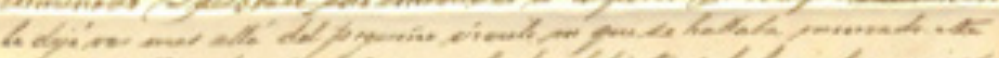

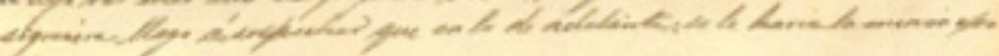
Kenen.

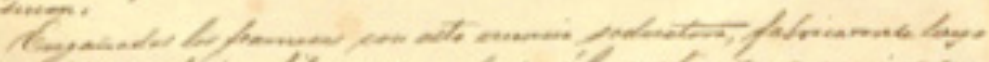

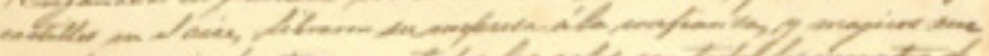

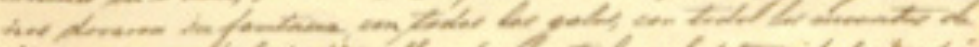

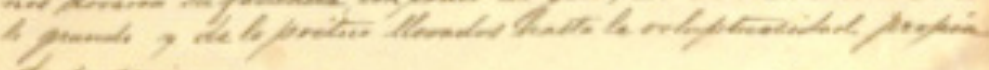

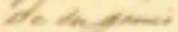

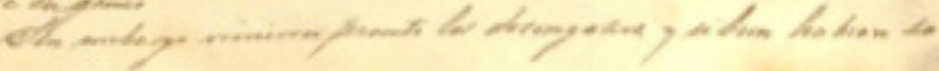




\begin{abstract}
This article is a chapter of the book in the press "Ignacio Orozco Sandoval. The deed of a forgotten Republican" I offer it this way to the readers of Chihuahua Today, because it has autonomy from the rest of the biography of colonel juarista, of whom I present below a brief semblance. It seems to me that this advance of the work can be useful to arouse interest in its subsequent reading, dedicated to the transit of this chihuahuan lawyer through the historical scenarios of his time and that has been studied fragmentarily and with multiple errors, product of a poor investigation and lack of materials.
\end{abstract}

Keywords: Chihuahua, Ignacio Orozco, Benito Juárez, Nation, Republic, France, Liberals.

\title{
NOTA INTRODUCTORIA
}

Nació en la Labor de San Isidro cercana al pueblo de Papigochi en 1813, perteneciente a la Nueva Vizcaya. Fueron sus padres Tomás Orozco Domínguez y Noberta Sandoval. Como el grueso de sus paisanos, fue labrador, vaquero, arriero. Aprendió las primeras letras en alguna de las rudimentarias escuelas de los pueblos y siguió cultivándose por su cuenta. Así, recibió el nombramiento de Jefe Político del Cantón Guerrero en 1851. Encabezó la lucha por las tierras de los labradores de San Isidro en esta década. Fue diputado en el congreso constituyente que expidió la Constitución local en 1858.

Entre 1858 y 1859 se desempeñó como segundo en jefe de las fuerzas liberales chihuahuenses que combatieron durante la Guerra de Reforma bajo el mando del general Esteban Coronado, participando en numerosas acciones de guerra, entre ellas los asedios y tomas de las ciudades de Durango y Guadalajara. En 1859 fue puesto al mando de la columna militar encargada de sofocar la rebelión conservadora dirigida por José María Zuloaga en el noroeste del estado. Confrontado con la élite política de la capital, encabezó una insurrección liberal en Chihuahua cuya causa 
central era el apoyo al gobierno constitucional. Fue Mayor General del Ejército comandado por el general Ignacio Zaragoza en 1860. Participó con ese grado en las batallas de Silao y Calpulalpan. Entró victorioso con las fuerzas del ejército liberal en la capital de la república en enero de 1861, bajo el mando del general Jesús González Ortega.

En 1862, de regreso a la entidad, fue electo Jefe Político del Cantón Iturbide, con cabecera en la capital del estado de Chihuahua. Entró en conflicto con el gobernador del Estado General, Luis Terrazas, por denunciar ante el presidente de la república los pocos o nulos aprestos que se hacían en territorio chihuahuense para defender a la nación frente al ataque del ejército francés. Se le encausó por este motivo y fue condenado al destierro poniéndosele bajo la custodia del gobernador Santiago Vidaurri. Se fugó en Cuatro Ciénega y, habiendo sido electo diputado suplente al Congreso de la Unión, se presentó en México rindiendo la protesta de ley. Al igual que muchos legisladores, colaboró con los sitiados de la ciudad de Puebla. En 1863 acompañó, como miembro de la comisión permanente del Congreso de la Unión, al presidente Juárez desde México hasta Chihuahua. Estuvo en San Luis Potosí, Saltillo y Monterrey con el gabinete juarista, durante la crisis motivada por la defección del gobernador neolonés Santiago Vidaurri. Su opinión fue decisiva para que el presidente Juárez decretara el estado de sitio en Chihuahua y depusiera en consecuencia al gobernador Terrazas, nombrándose en su lugar a Jesús José Casavantes, segundo del movimiento armado encabezada por Orozco en 1859.

En octubre de 1864, a la llegada del gabinete republicano a la capital del estado, fue convocado por el presidente de la república junto con el gobernador Ángel Trías y otros tres líderes políticos de estado a una Junta de Guerra, donde se diseñó la estrategia militar republicana. Enseguida se le nombró Jefe Político del Cantón Guerrero y comandante militar de la Línea de Occidente, en cuyo cargo recibió instrucciones directas del presidente Juárez. Hizo frente a las inconformidades de los vecinos del norte del Cantón Guerrero, quienes rechazaban las contribuciones de gue- 
rra. En 1866 sirvió de enlace entre el general Mariano Escobedo, comandante del ejército liberal en Nuevo León y Coahuila y el presidente Juárez, transportando papeles, dinero y armas de Monterrey a Chihuahua. Ese año, estando en campaña en Coahuila, escribió "La nación mexicana y el coloso de Europa", un largo ensayo sobre la guerra entre México y Francia, que me ocupa en este texto. En 1868 se graduó de abogado y en el anuncio de sus servicios, escribió: "defenderá gratis a los desvalidos, que por su pobreza no puedan poner en giro sus negocios”. Murió pobre de riquezas siendo diputado local el 10 de julio de 1872.

\section{LA NACIÓN MEXICANA Y EL COLOSO DE EUROPA}

El 15 de marzo de 1866, Jesús Carranza, notable vecino de Cuatro Ciénegas y un leal contribuyente a la causa republicana, le escribió a Benito Juárez una carta en la cual le decía:

Sr. Presidente don Benito Juárez. Donde se halle. Muy señor mío y de mi respetuosa consideración: El Sr. Orozco le remite a usted un artículo a fin de que se digne mandar que se publique en el Periódico Oficial o de cualquier otra manera. En consecuencia, a mi nombre y al de toda esta población, ruego a usted tenga la bondad de aceptar esta súplica en que está altamente interesada la causa nacional que usted defiende tan heroicamente (Tamayo, 1974, t. 10, p. 760). ${ }^{2}$

¿A qué artículo se refería Carranza y por qué su publicación interesaba altamente a la causa nacional? Se trataba de un largo ensayo escrito por el coronel Ignacio Orozco, en el cual se abordaban distintos aspectos de la guerra librada por México durante esos años en contra del imperio francés y sus colaboradores del partido conservador. Lo llamó "La nación mexicana y el coloso de la Europa” (I. Orozco, 1866) y fue escrito en Cuatro Ciénegas, aunque respondía a y se fincaba en reflexiones y conclusiones

2 Jesús Carranza fue el padre del presidente Venustiano Carranza. Durante la estancia de Benito Juárez en Chihuahua, en los tiempos de mayor penuria del gobierno y personal del presidente, le hizo un préstamo de mil pesos. 
maduradas por Ignacio Orozco en sus largas jornadas militares y políticas desde los primeros tiempos de la guerra de reforma y de la intervención francesa. A continuación, examino las principales líneas de sus contenidos.

Patria, nación, república, independencia, libertad, honor: los valores capitales

Atrae el concepto de "nación" usado por el autor desde el mismo título del escrito y reiterado a lo largo del mismo. Si bien la matriz de este sustantivo es milenaria, todavía en el siglo XVIII se le identificaba con "nacimiento", incluso en su edición de 1791 (Real Academia Española, 1791), el Diccionario de la lengua española consideraba ambas palabras como sinónimos. Y a lo más, se suponía que un grupo de "habitadores" de una comarca formaban una nación. Durante la fase colonial, a nadie se le hubiera ocurrido hablar de la "nación" mexicana y ni siquiera de la "nación" española. Los nombres con los cuales se identificaban los vecinos de las colonias hispanas tenían que ver con su localidad, su oficio, su raza. Así, alguien podía decirse "paseño", "arequipeño", "mexicano o mexicanero", "chihuahueño”, según su localidad de origen o residencia. También, como dice José María Luis Mora, lo usual era identificarse por el oficio, como carpintero, o herrero, o clérigo, o bien, alguno era de "nación apache", o de "nación español", aludiendo a su grupo racial originario. Desde luego, todos eran cristianos, el epíteto universal.

Las guerras de independencia de las excolonias españolas americanas produjeron un nuevo uso de la palabra nación. En México, comenzó a cobrar el sentido de comunidad política, extensa, que combinaba integrantes geográficos, religiosos, raciales. Más aún, que tenía entre sus componentes elementos de carácter subjetivo, propuestas de unidad, autonomía, aspiraciones compartidas. Los Sentimientos de la Nación, el famoso texto de José María Morelos, sin tener en mente todavía a los mexicanos, inauguraría en 1813 la era nacional. Sin embargo, todavía pasaría largo tiempo para que la idea de nación cuajara en la conciencia, no de la mayoría de los habitantes, pero sí de una minoría integrada por los elementos más vivos y actuantes de la sociedad. 
Después de 1821, cuando vino el bautizo y la adopción del nuevo gentilicio, comenzó a desarrollarse con mayor vigor el proyecto de construcción de una nueva nación. La declaración de independencia, como muchos documentos históricos y fundacionales de todo el mundo, comenzó con una ficción: “La Nación Mexicana que, por trescientos años, ni ha tenido voluntad propia, ni libre uso de la voz, sale hoy de la opresión en que ha vivido". En realidad, durante los tres siglos previos no existió tal ente llamado nación mexicana, como no existieron tampoco las naciones peruana, argentina, chilena, venezolana, etcétera. Sin embargo, en ese largo arco temporal, durante el cual permanecieron en estado larvario, sí se fueron fraguando los elementos que a la postre constituirían a cada una de ellas. De tal manera que empezar con una constatación de su existencia, aunque fuera esta ficticia, fue una manera adecuada para empezar su construcción. Si en los tres siglos previos se produjo la gestación, en 1810-1821 se produjo el parto.

De ninguna manera fue una iniciativa compartida por todos. Hasta 1867, con el triunfo definitivo del partido liberal, buena porción de las élites, abierta o subrepticiamente, mantuvieron en su agenda política el plan de regresar al sistema colonial, renunciando a la "nación". En el otro extremo de la disputa que fue extendiéndose a los ámbitos de la cultura, del pensamiento económico, de la religión, del régimen político, de la composición social y por tanto, de los privilegios y desigualdades, se ubicaron los sostenedores del partido liberal, de ninguna manera homogéneos en sus ideas. En muchos, quienes llevaron el peso de las dos guerras, nación y patria fueron sinónimos. Entendieron que fuera de una nación y una patria mexicanas ellos no tendrían cabida, sino como subyugados y en condiciones serviles. Esto responde a la pregunta: ¿Por qué la nación concitó tan fuertes adhesiones y compromisos?

El escrito de Ignacio Orozco abunda en esta línea de pensamiento y lo hace con la grandilocuencia y el ardor propios de la época: 
Bien saben nuestros conquistadores que la opinión los rechaza, que los mexicanos fieles partidarios de las repúblicas, detestan las monarquías; que su condición de ciudadanos libres, jamás se cambiará en la de esclavos miserables; y que justos apreciadores de la independencia de su Patria [sic], lo sacrificarán todo antes que entregarla a la rapacidad de los que a nombre de la civilización osen arrebatárselas. Firmes en esta resolución irrevocable, nunca medirán la fuerza ni contarán el número de sus enemigos que más de una vez se han arrastrado en la presente lucha, mordiendo el polvo entre gravísimas dificultades.

Los que se lanzan sobre nuestro suelo, se engalanan para asesinarnos unas veces con el ropaje de la civilización y otros con los andrajos de la hipocresía y del fanatismo... ¿Qué es pues lo que se quiere?, se pretende hacer de los mexicanos la servidumbre de nuestros humanitarios mentores, de nuestros caritativos maestros, se quiere que portemos librea, que nos convirtamos en lacayos a la Duport.

Muy apenas pueden hoy los franceses decirse dueños del terreno que pisan; nada establecen en ninguna parte, en todos se nota el desaliento, y la falta de energía es el signo característico de sus providencias. Sus leyes son como suerte de lotería, que en lugar del interés excitan la burla y el desprecio; en una palabra su dominio y la ocupación del País son tan imperfectas, que no se extienden ni una línea más allá de la distancia a que alcanzan sus bayonetas. No bien desocupan sus soldados una plaza cuando está ocupada por los nuestros Centauros [sic] de guerrillas los hostilizan en otras tantas direcciones opuestas, y cuando por la casualidad o por la fuerza han logrado forjar el imperio en alguna población, todo se derrumba, todo se desbarata al más ligero impulso de sus habitantes. Todo es pues risible, todo es ridículo en la farsa del imperio, donde parece que la insensatez, el crimen y la extravagancia constituyen sus principales elementos.

Esta conducta en tanto que es más torpe y grotesca hiere más vivamente nuestro decoro Nacional, y al paso que hace crecer el odio, despierta por todas partes la venganza contra los invasores.

Se insiste, sin embargo, en civilizarnos, en hacernos felices a fuerza de cubrirnos de oprobio y de baldón. El terror, la destrucción forman 
la enseña que los franceses llevan a todas partes, y la sangre mexicana enrojece la superficie de nuestro suelo. Ni siquiera existe entre nosotros un lugar, un pequeño recito donde no se lleve la desolación y el exterminio. los salvajes respetan alguna vez la inocencia de los niños, la inculpabilidad de los ancianos, la santidad de las vírgenes, pero los que nos traen la antorcha civilizadora, nada perdonan, y pasan por lo más santo, por lo más sagrado, arrasándolo todo para cubrimos de felicidad y ventura.

Si los franceses fueran tan dichosos como blasonan, no vendrían a dos mil leguas de distancia a desafiar la muerte en medio de las fatigas y de los más penosos sacrificios. Algo les falta pues, para que la dicha sea completa, porque de otra manera no abandonarían aquel Edén aquella tierra de delicias donde han nacido para todos los goces, para todos los planes inventados por el genio de la naturaleza. ¡Miserables!... por más que nos aparenten grandeza y bienestar son en realidad infinitamente más desdichados que nosotros: en nuestro bello suelo, con más y variadas producciones los inquietan, les causan envidia y forman otros tantos objetos de codicia que los arrastran a nuestras playas, como tristes aventureros, en busca de una suerte menos desgraciada.

Sabido es que se han levantado las armas contra nosotros que si nos han traído la guerra, no es que a esto los obligue una causa justa, un motivo noble, al contrario, el deseo de apoderarse de nuestros tesoros, el de robar nuestras riquezas, es lo único que pone en sus manos los instrumentos con que nos dan la muerte.

Fundado Napoleón III en este derecho, hasta ahora desconocido, y confiando demasiado en nuestra aparente debilidad, no se ha cuidado mucho de respetar el derecho de gentes, ni las leyes internacionales, y por esto es que nos hacen la guerra como suelen hacerla el pirata o el filibustero que no reconocen ningún principio de nacionalidad. Explicando de este modo la conducta desleal y vergonzosa con que Forey infringió el tratado de la soledad, no menos que la falta de fe con que Bazaine capturó al General Díaz en Oaxaca para apoderarse insidiosamente de aquel estado. Otros mil hechos podríamos citar en apoyo de esta verdad, pero por ser harto conocidos de la Nación los pasamos en silencio. 
Nuestro comportamiento en nada se parece al de nuestros opresores. Mientras que éstos nos hacen una guerra sin tregua, mientras que levantan patíbulos por todas partes para asesinar a nuestros prisioneros, nosotros, al contrario, tenemos abiertas las puertas de la hospitalidad, y respetamos todos los derechos y les damos a los suyos todo género de garantías. Pero repetimos que esta lucha es de contraste.

Nos falta ahora saber, si este género de ferocidad pueden emplearlo como un medio de mejorar su condición o si ella los alejó cada día más del fin que se proponen por objeto. Antes de que Maximiliano expedirá [sic] su famoso decreto de 3 de octubre de 1865, apenas se habrá dado algún caso entre Nosotros [sic] en que hubieran tenido lugar las represalias, pero después de la expedición de esa ley extraordinaria hasta por su redacción, la mayor parte de sus prisioneros perecen justamente en nuestras manos, semejante resultado por lo mismo que era natural, a nadie sorprende y todo el mundo aplaude nuestra cordura. Esto prueba que la justicia está de nuestra parte. Después que el llamado usurpador de México nos arroja el guante provocándonos a una guerra desastrosa, en que no se reconoce a la Nación como parte beligerante, para sus defensores fuera de la ley y manda que se maten brutalmente, declarándolos bandidos o salteadores de caminos.

Maximiliano sabe que el mal que se propuso evitar con esa ley de proscripción, muy lejos de cortarse o disminuirse, se ha aumentado hasta lo infinito; y sin embargo, obrando contra sus propios intereses, contra el testimonio de la experiencia y el conocimientos de la verdad, la ley permanece en pie sin que se haya atrevido a derogarla.

\section{MONARQUÍA CONTRA REPÚBLICA, LA PUGNA MUNDIAL}

Si traemos a colación a otro republicano nacionalista, al francés Félix Pyat, quien escribió un documento notable al presidente mexicano llamado "Carta a Juárez y sus amigos" publicado en ese mismo año de 1866, nos daremos cuenta del carácter universal o mundial que asumía la disputa entre monarquía y república, 
identificada con la nación, entre la tiranía y la libertad, al mismo tiempo que se compartían estilos y recursos literarios:

Nosotros somos vuestros hermanos... Vosotros sois republicanos: nosotros lo somos. Vosotros sois proscritos. Nosotros lo somos. Vosotros sois enemigos del imperio: nosotros lo somos. Vosotros representáis a México: nosotros hemos representado a la Francia. Nosotros hemos sido, como vosotros, electos por el pueblo, cuando era libre. El fraude y la fuerza nos han arrebatado, como a vosotros, nuestro mandato; pero no el deber de cumplirlo. Nosotros hemos representado dignamente a la Francia protestando contra la guerra de Roma. Otro tanto haremos con la guerra de México.

La bandera no es un metro de seda, colgado en la punta de un palo. El honor de la bandera estriba en los principios que ella representa y defiende. ¿Pero si en vez de defenderlos los combates, dónde se cifra entonces su honor? No en la victoria seguramente. El honor es la consagración del individuo á la unidad. Habiendo el hombre nacido sociable y elevándose á una vida colectiva cada vez más grande: familia, ciudad nación, raza, humanidad, \&c., el honor de un padre se cifra en la consagración á la familia: el honor de una familia, á la consagración á la nación; el honor de una nación, en la consagración á la humanidad. La bandera del honor es, en consecuencia, la que mejor representa el sacrificio á la unidad (V. Orozco, 2001, pp. 105-106). ${ }^{3}$

Para estos dos combatientes republicanos, la guerra no era entre la nación francesa y la nación mexicana, sino de ambas en contra del imperio, de la monarquía y de quienes traicionaban los principios y los intereses de Francia y de México:

Bien saben nuestros conquistadores que la opinión los rechaza, que los mexicanos fieles partidarios de las repúblicas, detestan las monarquías; que su condición de ciudadanos libres, jamás se cambiará

3 Pyat escribió y publicó su carta en francés y en Londres el año de 1865. Se la envió a Matías Romero, representante del gobierno republicano en Washington. Desde allí fue remitida a Paso del Norte donde residía en 1866 el gabinete presidido por Benito Juárez, quien ordenó su traducción e impresión ese mismo año. 
en la de esclavos miserables; y que justos apreciadores de la independencia de su patria, lo sacrificarán todo antes que entregarla a la rapacidad de los que nombre de la civilización osen arrebatárselas. Firmes en esta resolución irrevocable, nunca medirán la fuerza ni contarán el número de sus enemigos que unas de una vez se han arrastrado con la presente lucha, mordiendo el polvo entre gravísimas dificultades.

De acuerdo con el pensamiento de Orozco, "civilizar" a los mexicanos, exigía quitarles su autonomía y cancelar los esfuerzos ya medio centenarios para construir una nación y un Estado. En ello podían consentir sus apoyadores nacionales, los restos del viejo ejército disuelto por la revolución en enero de 1861, el clero - sobre todo sus altos jerarcas- y las élites que aspiraban a edificar una nueva aristocracia, con títulos nobiliarios y todo lo demás. Pero nunca pudieron conquistar la voluntad de cientos de miles de productores rurales, de arrendatarios de las fincas nacionalizadas ahora convertidos en propietarios, de pequeños comerciantes, profesionistas libres que formaban un gigantesco sector de la población que llevaba todas las de perder con la restauración del estatus colonial. De esta porción se nutrieron los famosos chinacos y las huestes del improvisado ejército republicano. Sin duda alguna, en este grupo se ubica nuestro biografiado, con su patriotismo o nacionalismo exaltados y amalgamados con el sentido del honor, tan caro a los rancheros y vecinos de sus lares. De allí que también este valor se convierta en una de las columnas sobre los cuales labra sus pensamientos:

Conservar la integridad nacional en toda su pureza, romper el yugo levantado sobre nuestra servís, despedazar de una vez las férreas cadenas de la tiranía, no deben ser para nosotros una simple creencia política ni un deber puramente social, al contrario debe respetarse como el credo de nuestra emancipación, como el dogma sagrado de nuestras libertades, como el vínculo religioso de nuestros derechos. Profanar sus principios, apostatar su fe, separarse de su creencia, es fundar el cisma de la disolución, es corromper el espíritu, es prosti- 
tuir el alma de nuestro ser independiente. Levantemos pues, en honor de la Patria este nuevo culto, rindámosle esta nueva adoración. Con nuestras reliquias, con nuestros preciados restos, erijamos sus altares, fundemos sus similares y ofrezcámosle allí, la oración sagrada, el holocausto grandioso de nuestra existencia.

Aquí están presentes los resabios de un vocabulario religioso, en el cual habían sido educados los mexicanos hasta entonces, con las escuelas en manos del clero. La adopción de un lenguaje propiamente republicano, laico, tardará quizá medio siglo, con la proliferación de escuelas civiles durante el porfiriato y sobre todo después de la Revolución de 1910. De hecho, las nuevas mentalidades ciudadanas empezaron a perfilarse en el ámbito educativo, cuando en la primera década después de la independencia los niños estudiaban en los primeros "catecismos cívicos", los cuales, conservando la forma de los religiosos, modificaban el contenido, por ejemplo, en una cuestión clave: ¿De dónde emana la autoridad? En lugar de la centenaria respuesta: de Dios, los infantes respondían en coro: del pueblo.

No obstante, el rastro de las concepciones religiosas, para Orozco y los de su clase, el compromiso con la Patria, escrita con mayúscula, representaba la obligación suprema del individuo. En ello estribaba una de las diferencias cruciales con el ideario de los conservadores, para quienes el fin último de cada uno era servir a Dios y a la Iglesia. Esta emancipación del credo religioso les permitía asumir la gestión de sus vidas y de sus intereses por sí mismos, en lugar de la supeditación a los administradores del culto católico.

\section{VASALLOS CONTRA CIUDADANOS}

Si en el párrafo transcrito antes es notable el lenguaje venido de las iglesias, en el siguiente deben resaltarse dos conceptos, ciudadano y vasallo: 
Si los hombres por una ceguedad incomprensible quisieran despojarse de la venda que les impide ver a los franceses en toda su deformidad, se desengañarían desde luego de que son ellos la primera víctima sacrificada a su ambición. Estos no les han entregado su suerte sino porque aquellos han contraído expresa y tácitamente el solemne compromiso de asegurarles la paz y todo cuanto atraen al progreso y bienestar de cada individuo. En efecto era lo menos que podrían esperar unos hombres que cambian la libertad por la tutela y el nombre de ciudadanos por el de vasallos.

En estas dos categorías, como lo saben los teóricos de la ciencia política, se sintetiza la diferencia entre el mundo de los modernos y el de los antiguos. Con la palabra súbdito o vasallo, se aludía a un individuo-pieza del cuerpo social, por antonomasia pasivo, sin otro designio que servir a su señor, incluso adoptando el credo religioso que este profesase. No se le concebía deliberando sobre asuntos competencia de la autoridad y menos aun oponiéndose a los mandatos de esta. En lugar de libertad, tenían tutela, como dice Orozco. El tránsito de una condición a otra implicó un proceso sangriento y, al decir de Alfonso Reyes, demasiado rápido, tanto que, según afirma, los mexicanos fuimos amamantados con ajenjo, en vez de leche, aludiendo a la circunstancia de que nos acostamos súbditos y nos despertamos ciudadanos, para enfatizar la manera diferente como ocurrió en Europa, donde esta etapa duró siglos. En efecto, estrenamos instituciones, aprendimos a elegir, a escribir sin censuras o a pesar de ellas, a enseñar y aprender fuera de los cánones eclesiásticos, a leer los libros que nos placieran, a casarnos sin parar mientes sobre el credo religioso del otro o la otra y, por último, a pensar por cuenta propia, sin una religión obligatoria. Conquistas alcanzadas a partir de 1821, pero, sobre todo, entre 1857 y 1860.

Ignacio Orozco pensaba y actuaba en 1866 como un ciudadano, carácter reivindicado con orgullo en las filas liberales, comprendido y adoptado a fuer de recorridos largos y batallas sin fin por un sinnúmero de "chinacos", las guerrillas que acosaban a los 
franceses y tomaban las plazas apenas salían de ellas los regimientos invasores, según lo explica el mismo ensayo comentado.

\section{EL DESPRECIO POR LOS TRAIDORES A LA CAUSA NACIONAL}

La guerra de la intervención francesa en México tuvo al menos tres vertientes: una internacional, visible en las acciones emprendidas por las principales potencias de la época. El país era presa del imperio colonial francés, que disputaba con otras potencias europeas el dominio de vastos territorios en América, Asia y África. Se jugaban aquí cartas fundamentales de la diplomacia y de las confrontaciones militares de Francia, España, Inglaterra, AustroHungría, Bélgica, Prusia, El Vaticano y Estados Unidos. Fue también internacional porque enfrentó en el combate a dos entidades nacionales: México y Francia. Por último, fue una cruenta guerra civil, prolongación de la guerra de reforma librada entre liberales y conservadores. A esta cara del conflicto, se refiere otra parte del texto de Ignacio Orozco, cuando se lanza en contra de quienes aliados del ejército extranjero, combaten a las huestes nacionales:

el Archiduque de Austria, su gentil Carlota, más crédulos todavía que el héroe de Cervantes, que aquel genio singular que supo descubrir las ínsulas en tierras, aunque sin esperanza de conservar la presa que se desliza de sus manos, tiran de vez en cuando una mirada desconsoladora sobre sus aliados, sobre aquellos hombres que a la luz de mil antorchas misteriosas, fueron a buscarlos hasta los oscuros bosques de Miramar, para darles un trono de diamantes, para poner en sus manos su cetro, que los conquistara un hombre augusto, una página brillante en los fastos de la reyedad. Pero esos hombres celestiales, no existen ya sobre la tierra, han volado a las esferas, y aunque es cierto que nos ha dejado sus manos, solo sirven para rodear el sepulcro de nuestros reyes, ipara cuidar sus mármoles y quemar incienso en sus mausoleos más duraderos todavía que lo han sido sus timbres imperiales!

Sí; ¿mas cuánto darían esos reptiles, salidos del fango de la iniquidad, por no haber emprendido esta obra que tanto punza sobre su 
conciencia? Ellos no piensan ya sino en los peligros que corren, en los riesgos que les aumentan; su infamia, su traición se les presenta a cada paso como el genio de la muerte: mil espectros se levantan a su vista, ya como ángeles exterminados cercados por el abismo, o como fantasmas armados con la seguridad que un día no lejano separará sus cabezas...

En medio de su eterna agonía, de su constante angustia, ni los protegerá Maximiliano, ni los socorrerá Napoleón, este carece de fuerzas y de inteligencia y aquel no tiene ni fuerzas ni habilidad. ¡Desgraciados!... ¡Vosotros os halláis perdidos! ¿Dónde están las promesas con que os sedujo Napoleón III? ¿Qué habéis hecho del precio de vuestra degradación? ¿Contáis acaso con la paz, el engrandecimiento y la riqueza, que os ofrecieron para vuestro suelo? Si os deja la vergüenza, levantad la vista y dejadla caer en torno de esa tierra bendita sobre que habéis nacido y espantaos entonces con esos montones de cadáveres, con esos torrentes de sangre, con ese fuego abrasador que esparce por todas partes la desolación, el espanto y la muerte. Horripilaos delante de este cuadro tremendo que os presenta la obra de vuestras propias manos, huid pavorosos, y si os quedan todavía algunos restos de sensibilidad, si os lastimáis aún de los gemidos de la desventura, paraos un instante y escuchad el grito de millares de seres sacrificados a vuestra perfidia. Enseguida tomad, si queréis, esas imágenes trazadas por la amargura, esculpidas por el llanto, sembradas por la desesperación y reproducidas mil y mil veces en torno vuestro por el prisma del dolor que los despedaza, examinadlos y si os sentís entonces conmovidos, si os arrepentís de que os hallan trocado en instrumento de martirio, rendidles un homenaje de respeto, volved sobre vuestros pasos y sacrificadles vuestra existencia en las aras de la Patria.

Nada desencaminado andaba Ignacio Orozco en su diatriba contra los apoyadores mexicanos del imperio. Por cierto, nunca le merecieron al monarca importado otra cosa que el desprecio, según puede advertirse por el documento mencionado enseguida.

El 15 de mayo de 1867, Maximiliano fue fusilado en el Cerro de las Campanas y la capital del país cayó en manos de los li- 
berales el 20 de junio. En las oficinas del Palacio Nacional, ocupadas por Maximiliano, entre otros enseres y escritos, quedó un libro guardado en secreto, empastado con lujo, conteniendo un pequeño diccionario onomástico para uso del emperador y en el cual se consignaban fichas biográficas de un buen número de colaboradores mexicanos del imperio. La tarea para confeccionar y organizar estos datos le fue confiada al ingeniero belga Félix Elion, jefe civil del gabinete de Maximiliano y hombre de su confianza. La sorpresa por el hallazgo debe haber sido mayúscula para los republicanos, quienes, considerando la relevancia del documento, lo publicaron bajo el título de "Los Traidores pintados por sí mismos". Para que nadie dudara de la autenticidad, pusieron una certificación inicial:

El infrascrito, Oficial Mayor de los Ministerios de Relaciones Exteriores y Gobernación, certifica que lo que sigue está tomado de un libro que dejó D. Fernando Maximiliano de Hapsburgo [sic], en las piezas del Palacio nacional, en que estaba su Secretaría particular; que la parte en español de dicho libro está fielmente copiada, y la parte en francés correctamente traducida. México, Diciembre 24 de 1867. ${ }^{4}$

La lista, ordenada por alfabeto, abarca 263 nombres y apellidos, comprendiendo a lo más granado del partido conservador. Podría esperarse que el juicio de Maximiliano y de sus consejeros extranjeros sobre sus partidarios y colaboradores, fuese benevolente y aún de gratitud. Sin embargo, ninguno de los dos sentimientos aparece en las frías e implacables descripciones. Tomemos como ejemplos ilustradores a tres de los más connotados monarquistas.

El primero de ellos, Miguel Miramón, el "Joven Macabeo", que a resultas del golpe de estado de Tacubaya asumió de facto el poder ejecutivo. Fue un eficaz militar durante la primera etapa de la guerra de Reforma —entretanto se conformaba el ejército libe-

4 “Los traidores pintados por sí mismos", Libro Secreto de Maximiliano en que aparece la idea que tenía de sus servidores. México, Imprenta del Gobierno, en Palacio, a cargo de José María Sandoval, 1867. 
ral- y, al final de su vida, el brazo derecho de Maximiliano, con quien compartió el paredón. Su registro decía en algunos párrafos:

Entró al Colegio Militar en 1846. Debido á su buena inteligencia ascendió en un año á cabo, y después á sargento; y como oficial de artillería á los grados de subteniente y teniente. Comenzó en esta época á entregarse á su pasión por el juego...siendo capitán de cazadores de infantería en Toluca, perdió un día el dinero de su compañía, de que era depositario...

...se unió a algunos descontentos, con ayuda de ellos se hizo dar por Zuloaga el título de Presidente sustituto... Se preparó entonces á marchar sobre Veracruz, donde Juárez había situado su gobierno. Impuso algunos préstamos forzosos, reunió los fondos que había en las cajas públicas, y con el pretexto de atender á las necesidades de su ejército, dirigió este dinero hacia la tierra caliente, y después, en lugar de enviarlo al campo frente á Veracruz, lo hizo embarcar en Alvarado por su propia cuenta. Tal es el origen de su fortuna.

De acuerdo con Díaz, su Ministro de Hacienda, se entregó a toda especie de exacciones. Cansado de su insubordinación y de su conducta, Zuloaga le quiso retirar su título de Presidente sustituto; pero Miramón por toda respuesta se nombró Presidente, e hizo arrestar á Zuloaga",

Juan Almonte, otro de los sostenedores mexicanos del Imperio no resulta mejor librado. En la extensa parrafada que se le dedica, es acusado de veleidoso, traicionero, apoyador siempre de los triunfadores: Cuando Santa-Anna se puso al frente del ejército mexicano, Almonte intrigó mucho para hacerse nombrar por el Congreso vicepresidente. No consiguió mas que caer en desgracia. Se ligó íntimamente con Juárez y con muchos diputados progresistas de los más exaltados... Se retiró á la vida privada hasta el tiempo de Comonfort. Se declaró en esta época gran partidario de la desamortización de los bienes del clero...

El carácter de Almonte es frío, avaro y vengativo. No ha hecho nunca la guerra, y debe su grado militar, á que en tiempo de Morelos fue nombrado coronel, siendo aún niño. 
Al tercero de los seleccionados, el "Príncipe de la Iglesia", arzobispo Antonio Pelagio Labastida, uno de los personajes centrales del Partido Conservador, cercano al Papa Pío IX, el libro secreto de Maximiliano le dedica un amplio espacio, pues incorpora la breve biografía escrita por un agente francés. Entre otros datos, el informante dice que compró el nombramiento de obispo de Puebla:

Como resultado de las notas del Nuncio, el nombramiento fue aprobado sin dificultad, y el Nuncio recibió de Monseñor Labastida, en recompensa de su servicio, cuatrocientas onzas de oro, y a Monseñor Munguía le regaló un anillo pastoral, adornado de brillantes, que valía igual cantidad.

Maximiliano supo también sobre la participación del dignatario católico en el trabajo para azuzar a los militares y provocar el golpe contra la Constitución de 1857:

Sus agentes, miembros del clero y militares separados del ejército, se esparcieron secretamente por todos los Estados, los unos, para percibir secretamente el dinero de los curatos, y los otros, para seducir á las tropas por promesas y por dinero.

El padre Miranda, principal agente de Monseñor Labastida y el alma de la conspiración, iba por todas partes disfrazado, tratando con los obispos y dirigiendo con la mayor audacia todos los hilos que debían hacer estallar la revolución, que dio por resultado hacer verter durante tres años consecutivos la sangre de los inocentes.

Tal es la vida pública de Monseñor Labastida; en cuanto a su vida y a su conducta privada, me reservo hacerlas conocer más tarde a V. M. Si me hace el honor de pedírmelas: los hechos y los actos que resultan corroborables, se refieren a su vida pública... De V. M. muy humilde y obediente servidor, Maury.

El libro secreto habla de un Maximiliano precavido, que intentó formarse un juicio realista sobre sus asociados. Pueden estos informes ser analizados desde muchos ángulos, entre otros, el de su veracidad. Resalto aquí uno de ellos: el menosprecio que le me- 
recían al llamado Emperador de México el grueso de los dirigentes y funcionarios venidos del partido reaccionario. La historia ha recogido múltiples episodios en los cuales se expresa esta actitud de los conquistadores hacia integrantes de los conquistados, que se cambian de bando, para conspirar o pelear en contra de sus compatriotas. Imposible que no venga a la mente el viejo adagio, muy a propósito: "Roma desprecia a los traidores".

\section{LA APUESTA NORTEAMERICANA}

Los Estados Unidos entraron en la Guerra Civil el 12 de abril de 1861. La intervención francesa comenzó en México a finales de ese año y el ejército galo inició las hostilidades en los inicios de 1862. Si bien las conspiraciones e iniciativas monárquicas tenían en México décadas de existir, es claro que en el ámbito de la geopolítica mundial la guerra interna norteamericana fue un factor de primer orden en el diseño de la estrategia napoleónica para instaurar un protectorado francés en el continente americano. A lo largo de la guerra entre México y Francia, el gobierno norteamericano mantuvo un estado de neutralidad, aunque siguió reconociendo a la República como el régimen legítimo del país. El gabinete de Juárez siempre estuvo representado en Washington por el embajador Matías Romero (antiguo discípulo del mismo Benito Juárez en el Instituto Literario de Oaxaca). Abraham Lincoln, el mandatario norteamericano, ordenó una estricta neutralidad respecto al conflicto armado mexicano, aunque, en alguna ocasión, permitió la venta de carros y mulas al ejército francés desde Nueva York. Respecto al ejército mexicano, hasta en la rendición de la confederación se impidió la venta de armamento. Alcanzado el triunfo, comenzaron a fluir fusiles y municiones comprados en la frontera, principalmente en Tamaulipas y Coahuila.

Muchas voces entre los unionistas asociaron la separación de los estados esclavistas con el intento de instalar un imperio en México bajo el patrocinio de Napoleón III, que en esos años impulsaba una estrategia expansionista en varios países del orbe, como Argelia y Vietnam. Justo del primero provenían los batallo- 
nes de zuavos, tropas coloniales reclutadas por el ejército francés y a los que hace alusión Ignacio Orozco en su ensayo. Aun en los primeros meses de 1866, cuando se escribió el texto que examino, se ofrecía la vislumbre de la derrota que sufriría el imperio de Maximiliano, faltaba mucha cinta que correr de esta película. Las tropas francesas mostraban signos de agotamiento al advertir que dominaban las plazas, pero no podían hacerse del control del territorio. Sin embargo, distaban mucho de haber sido derrotadas y la moneda se encontraba todavía en el aire. Se rumoreaba ya su retiro, no obstante, aún marchaban en ciudades tan lejanas del centro como Chihuahua. Por esta razón, Orozco, entre muchos otros, le concedía tanta importancia a la terminación de la Guerra Civil norteamericana y al apoyo que la causa republicana pudiese recibir de Estados Unidos. Esta visión coincidía con aquellos que, en este país, exigían la expulsión de los franceses de México y por consecuencia la caída del emperador, al que miraban como un aliado de los sudistas. Para corroborar esta afirmación, en septiembre de 1865, el emperador mexicano se propuso traer al país a contingentes de esclavistas a territorio mexicano. Incluso emitió una ley que, prohibiendo formalmente la esclavitud, en los hechos, la reestablecía (Chávez Orozco, 1961). ${ }^{5}$

5 El decreto de Maximiliano, fechado el 5 de septiembre de 1865, establecía en sus artículos 1 y 2: "Con arreglo a las leyes del Imperio, todos los hombres de color son libres por el solo hecho de pisar el territorio mexicano. Celebrarán con el patrón que los haya enganchado o que los enganche, un contrato por el cual se obligará aquél a alimentarlos, vestirlos, alojarlos y asistirlos en sus enfermedades, así como a pagarles una suma en dinero, conforme a las condiciones que se estipularán entre sí, y además entrará en beneficio del operario, una cantidad equivalente a la cuarta parte de este salario, en una caja de ahorros, de cuya caja se hablará más adelante; el operario se obligará a la vez con su patrón, a ejecutar los trabajos a que sea destinado, por el término de cinco años al menos, y diez años a lo más. En caso de deserción, el operario aprehendido será destinado sin sueldo alguno a los trabajos públicos, hasta que el patrón se presente a reclamarle. El patrón se obligará a mantener a los hijos de sus operarios. En caso de muerte del padre, el patrón se considerará como tutor de los hijos, y éstos permanecerán a su servicio hasta su mayor edad, bajo las mismas condiciones que lo estaba el padre". Decreto de Maximiliano, de fecha 5 de septiembre de 1865. Maximiliano y la restitución de la Esclavitud en México 1865-1866. Investigación y prólogo de Luis Chávez Orozco, SER, México 1961. 
En este contexto Ignacio Orozco remarcaba en su documento el presunto apoyo que recibiría la causa republicana en Estados Unidos:

Ahora, precisamente ahora, que las relaciones de los Estados Unidos con la Francia se enturbian por momentos... Sabemos ya que en aquella república, se tiene la certeza de que la Francia ha fomentado y sostenido la rebelión de los confederados en el Sur, que tanto en la prensa como en la tribuna, se sostiene con tanto calor como decisión, que la prolongación de la guerra, es obra de sus manejos; que su influencia ha retardado el término de la paz y finalmente; que debiendo haber conservado más perfecta neutralidad respecto de sus negocios interiores, ha roto este principio para abordar pretensiones mezquinas que la deshonran y que atacan bruscamente sus intereses nacionales.

En compendio sabemos también que acerca de este punto son tan exageradas las exigencias de los anglo-americanos que no temen insinuarse ante el gobierno de la manera más pública para que sin retardo exija de los agresores los millones de pesos invertidos en la contienda. Se cree además por la mayor parte de los ciudadanos que la guerra del sur y la de México son una misma cosa, y que mal puede considerarse concluida la primera, sin que lo esté igualmente la segunda.

Es probable que alguna parte del texto haya sido escrita tiempo atrás y pegado en la nueva versión, pues se habla de la prolongación de la guerra civil norteamericana cuando esta ya había concluido. De cualquier manera, el argumento no pierde vigencia, pues lo que Orozco desea recalcar es cómo en Estados Unidos se veía la derrota de los confederados con la de los franceses en México totalmente vinculadas.

\section{LOS HOMBRES LIBRES: UNA CONDICIÓN COMPARTIDA}

A lo largo del extenso documento, se advierte una intención sostenida: convencer a los mexicanos de luchar contra los invasores 
y sus aliados, comprometiéndose con la defensa de la república. Ignacio Orozco emplea argumentos dirigidos a los mismos conservadores para hacerles ver su incongruencia y la perdición que les espera, pero dirige sus principales disparos a la conciencia de los libres, machacando los temas de la dignidad y del honor pisoteados por los invasores:

Nada por cierto tenemos que esperar del charlatán francés nada que permitirnos de su rumbosa falsedad, pero suponiendo aún, que nos cargasen de oro, que nos atestasen de riquezas ¿Habría un solo mexicano que quisiera comprarlas a cambio de su dignidad? ¿Habría quien los pagase al precio inestimable de su decoro? Que responden todos los hombres que saben lo que valen, los que no vacilan, en preferir la muerte a una dicha que suicida su reputación. Añadimos sin embargo, que el ciudadano libre, que el hombre que tiene la conciencia de su dignidad, en nada se asemeja al esclavo, cuya condición parece colocarlo muy distante de la esfera que circunda a los seres inteligentes.

¿Pero para qué cansarnos? ¿Por qué llevar más adelante la demostración? Los mexicanos nos encontramos en esta seria disyuntiva o doblarnos a la Francia vergonzosamente la servís para que nos ponga el yugo, o aceptamos el duelo con que nos reta esta potencia. Es evidente que no podemos resignarnos a lo primero, por que seríamos víctimas de la infamia; luego entonces tenemos que decidirnos por lo segundo cualquiera que sean las consecuencias del suceso. En este caso es lógico persuadirse de que tenemos que lanzarnos al combate, que levantar el guante, que pelear con valor, que luchar con decisión.

Esta actitud y mentalidad, en las cuales insiste nuestro biografiado, de ninguna manera lo hacen ver como una rara avis en el conjunto de los luchadores republicanos. En su natal Chihuahua, en Coahuila y en otras entidades, vecinos de los pueblos se alistaban para combatir a los invasores. En el primero de los estados, no obstante los conflictos políticos y las reticencias de funcionarios estatales, en la amplia geografía estatal se levantaron listas de volun- 
tarios que se ofrecían para pelear en las fuerzas de la República. En el Cantón Bravos, que comprendía los pueblos de Paso, San Lorenzo, Senecú, Zaragoza, Tres Jacales, Guadalupe, San Ignacio, Carrizal y Carmen, se inscribieron mil setecientos ochenta varones entre los dieciséis y los cincuenta años de edad. Además de su estado civil, edad y oficio, se agregó una columna para indicar si era o no voluntario. La mayoría de los jóvenes figuran en este rubro. Otras de estas hojas informan sobre las cooperaciones en armas o dinero con las cuales se apuntaban los lugareños de estos pueblos. Se pueden leer allí cantidades diversas, casi todas ínfimas, y la aportación de armas de variados calibres y especies, con seguridad inservibles para la guerra con los franceses, pero que, para sus dueños, quienes vivían, al igual que sus padres en medio de una recurrente confrontación con las naciones indias, eran instrumentos de sobrevivencia (Archivo Histórico Municipal de Juárez, c. 1894).

Una nota de El Chihuahuense (Archivo Histórico Municipal de Chihuahua), semanario fechado el 14 de julio de 1863, dirigido por José María G. del Campo, consignaba:

Los fronterizos. Debemos a la espontaneidad de los vecinos del Cantón Bravos el auxilio de armas que han donado al Estado, ellos y otros mexicanos y vecinos del Nuevo-México, residentes en territorio que perteneció a Chihuahua. Muchas armas se hubieran traído por la generosa comisión, si ella no rehusara las de diverso calibre, construcción y especie, que le presentaban los bondadosos fronterizos y de que tanto necesitan en su apartada comarca.

¿Qué movía, sino el patriotismo, a estos pastores y labradores de Paso del Norte y de los otros minúsculos pueblos ribereños para ceder bienes e instrumentos tan preciados como las armas? A fin de cuentas, los fuegos de la guerra librada por México ardían a dos mil kilómetros de sus casas y a cuarenta días de camino por lo menos (V. Orozco, 2012).

\section{LA CONTINUIDAD DE LA LUCHA POR LA INDEPENDENCIA}


Ignacio Orozco sigue la línea del pensamiento liberal que enlaza a la guerra de independencia con la de reforma y la intervención francesa, considerándolas como hitos de una larga lucha del pueblo mexicano por su liberación.

Recordemos que ha habido un Hidalgo, un Allende, y un Morelos que nos enseñaron como se da principio en la carrera de la independencia, que nos trazaron su camino y que fueron los primeros en ofrecerse al sacrificio para instaurarla; pero jamás olvidemos que ha habido también un Iturbide, un Bravo y un Guerrero que nos dieron la pauta para perfeccionar esta obra grandiosa, digna por cierto de los genios justos que supieron llevarla hasta su consolidación.

Esta pauta de continuidad histórica permitió al partido liberal legitimarse ante sus mismos adherentes y ante el exterior. Al reivindicar las anteriores revoluciones como propias, se vistió con el manto de la mexicanidad y pudo convertirse en la representación nacional. Por su parte, el partido conservador, al repudiar a la independencia, teniéndola como la fuente de todos los males y reclamar una vuelta al sistema colonial, perdió a la larga cualquier posibilidad de encabezar a una nación a la cual sus principales dirigentes veían en todo caso como un aborto, del que había surgido una entidad sin viabilidad alguna. De allí su eterna esperanza de un gobierno ejercido por algún príncipe católico de alguna casa real europea.

El párrafo transcrito del opúsculo de Ignacio Orozco insiste en la concepción del liberalismo al poner a los héroes de la independencia (hasta ese momento Agustín de Iturbide incluido, aunque cada vez menos aceptado) como los padres de la patria, especialmente a Hidalgo, Allende y Morelos. Es probable que conociera entre otros, el famoso discurso pronunciado por Ignacio Ramírez en la Alameda Central de la Ciudad de México el 16 de septiembre de 1861, cuando se aguardaba la intervención europea. Se recordará que en esa pieza oratoria tan celebrada, el Nigromante dijo: 
...solo el gran libertador de México ha tenido valor para llamar, las primeras, bajo su glorioso estandarte, a las turbas envilecidas... ¿De dónde venimos? ¿Adónde vamos?... si nos encaprichamos por ser aztecas puros, terminaremos con el triunfo de una sola raza, para adornar con los cráneos de las otras el templo del Marte americano, si nos empeñamos en ser españoles, nos precipitaremos voluntariamente en el abismo de la reconquista, pero no, nosotros venimos del pueblo de Dolores, descendemos de Hidalgo... (Ramírez, 1861).

Por otra parte, eran comunes los escritos y discursos de los ideólogos de mayor connotación en el partido liberal como Ignacio L. Vallarta, una de las eminencias jurídicas del siglo XIX, quien explícitamente postulaba que la revolución desplegada durante la guerra de reforma era la misma comenzada en 1810 (Archivo Histórico CONDUMEX, f. suelto). ${ }^{6}$ Ignacio Orozco también advirtió de seguridad el empeño de Benito Juárez, quien en su peregrinaje por el territorio nacional colocó siempre un retrato de Hidalgo en donde sea que despachara y abrió el libro de visitas en la casa donde este naciera, según lo hemos narrado en otro capítulo. Los conservadores, por su parte, a regañadientes, aceptaban a Hidalgo y a los otros líderes insurgentes como los héroes nacionales, solo porque su figura había cobrado ya una enorme popularidad, presidiendo el festejo anual del 16 de septiembre, aniversario de la independencia, que invariablemente se celebraba en todo el país. Eran notables los discursos y textos que se leían en tales ocasiones en las principales ciudades, convirtiéndose en documentos aleccionadores que circulaban en folletos leídos en plazas, tende-

6 Una disertación más clara es la de Ignacio L. Vallarta, quien escribió: "El curso de mis ideas me ha llevado a tocar un punto cuya matemática demostración es necesaria: la revolución que hoy trabaja a nuestra Patria no es más que el complemento de la que Hidalgo inició en Dolores. La filosofía de nuestra Historia pone de relieve esa verdad... todos aquellos... elementos que señalé como enemigos de la revolución de Dolores y que viven entre nosotros, tienen un partido en cuyas tendencias respiran...El partido realista... se ha transformado, cambiando solo de nombre, en el partido conservador... que ha comenzado por infamar la memoria de Hidalgo y de nuestros héroes: dígalo si no la desvergonzada historia de Alamán...". Discurso pronunciado por el C. Ignacio L. Vallarta en Sayula, el 16 de septiembre de 1858, en conmemoración de la independencia nacional. Folleto suelto, Archivo Histórico CONDUMEX. 
jones y zaguanes. Contra esta imagen popular de Miguel Hidalgo, se alzaban la prensa y los voceros e ideólogos del conservadurismo. El principal de ellos, Lucas Alamán, eminente historiador y político, tenía una opinión pésima y fundada acerca de la Guerra de Independencia, a la cual consideraba la fuente de todos los males sufridos por el país.

\section{EL LLAMADO FINAL}

El ensayo concluye con una vehemente convocatoria:

¡A las armas compatriotas, aprovechad la situación que os presentamos y contad con la gloria que os brinda la esperanza de un triunfo que muy pronto coronará nuestra frente con los laureles que os disputan las falanges del invasor! Cuatro Ciénegas, febrero 10 de 1866. Ignacio Orozco.

Este tipo de exhortaciones eran el pan de cada día en las guerras civiles y más aún en contra de invasores extranjeros. La particularidad de este, firmado por el coronel Ignacio Orozco, residía en que estaba respaldado por los hechos, en otras palabras, provenía de un hombre que había empeñado su vida en hacer valer sus palabras.

\section{REFERENCIAS}

Real Academia Española (1971). Diccionario de la Lengua Española. Madrid: Real Academia Española.

Chávez Orozco, L. (inv. y pról.). (1961). Maximiliano y la restitución de la Esclavitud en México 1865-1866. México: Secretaría de Relaciones Exteriores.

Orozco, I. (1866). Gabinete de manuscritos de la Biblioteca Nacional de México.

Orozco, V. (2001). Carta a Juárez y sus Amigos de Félix Pyat y Los informes de Reuben Creel. Chihuahua, Chihuahua: Universi- 
dad Autónoma de Ciudad Juárez/Instituto Chihuahuense de la Cultura.

Ramírez, I. (1861). Discurso pronunciado en la Alameda Central de la Ciudad de México el 16 de septiembre de 1861. México: Varias ediciones.

Tamayo, J. L. (1974). Benito Juárez: Documentos, Discursos y Correspondencia. Tomo X. México: Secretaría del Patrimonio Nacional.

\section{ARCHIVOS HISTÓRICOS}

Archivo Histórico CONDUMEX.

Archivo Histórico Municipal de Chihuahua (AHMCh).

Archivo Histórico Municipal de Juárez (AHMJ). 